\title{
Reducing Capacity of Smart Charger for Electric Vehicles on Single-Phase Three-Wire Distribution Feeders with Reactive Power Control
}

\author{
Hidenori Tanaka* Student Member, Takaaki Wakimoto* Student Member \\ Toshihiko Tanaka* Senior Member, Masayuki Okamoto** Member \\ Eiji Hiraki*** Member
}

(Manuscript received Dec. 20, 2013, revised May 1, 2014)

\begin{abstract}
This paper proposes a new control algorithm to reduce the capacity of the previously proposed smart charger for electric vehicles (EVs) on single-phase three-wire distribution feeders using reactive power control on the source side. The basic principle of the proposed reactive power control algorithm is discussed in detail. It is shown that controlling the reactive power on the source side reduces the capacity of the previously proposed smart charger. A digital computer simulation is carried out to confirm the validity of the proposed control algorithm using PSIM software. A prototype experimental model is constructed and tested. The experimental results demonstrate that balanced source currents with a power factor of 0.9 , which conforms to Japanese regulations, are obtained on the secondary side of the pole-mounted distribution transformer during both the battery charging and discharging operations in EVs reducing the capacity of the smart charger by $31 \%$ in comparison to that of the smart charger with the previously proposed control algorithm.
\end{abstract}

Keywords: single-phase three-wire distribution system, smart charger, three-leg inverter, constant dc-capacitor voltage control, single-phase $d-q$ transformation

\section{Introduction}

Smart meters are now installed for household consumers in Tokyo and Kansai electric power companies' areas, but not for commercial consumers yet. The smart meters can report to the electric power companies the power consumption conditions of each household consumer. It is natural that household electricity prices for consumers with high-quality power consumption should be lower than that for consumers with low-quality power consumption in the near future. Thus, each household consumer will be responsible for improving the power consumption conditions. Single-phase threewire distribution feeders are used for household consumers in Japan. Load conditions for household consumers are always unbalanced. These unbalanced conditions cause unbalanced voltages on the secondary side of pole-mounted distribution transformers. The secondary-side source currents of the pole-mounted distribution transformers are also unbalanced. It is well known that these unbalanced source-current conditions increase losses in pole-mounted distribution transformers. Power companies compensate for these losses, although the losses are caused by household consumers. There

\footnotetext{
${ }^{*}$ Department of Electrical and Electronic Engineering, Yamaguchi University

2-16-1, Tokiwadai, Ube, Yamaguchi 755-8611, Japan

** Ube National College of Technology

2-14-1, Tokiwadai, Ube, Yamaguchi 755-8555, Japan

*** Graduate School of Natural Science and Technology, Okayama University

3-1-1, Tsushima-Naka, Kita-ku, Okayama 700-8530, Japan
}

are a large number of pole-mounted distribution transformers in Japan, so the total economic losses are great. It is also natural that household consumers should be responsible for compensating the losses in pole-mounted distribution transformers in the near future.

On the other hand, electric vehicles (EVs) are now commercially available. The Mitsubishi i-MiEV is a five-door hatchback electric kei car, and the Nissan LEAF is a mediumsize five-door hatchback electric car. The lithium ion batteries equipped in the $\mathrm{i}-\mathrm{MiEV}$ can store $16 \mathrm{kWh}$, whereas in the LEAF, the maximum stored power is $24 \mathrm{kWh}$. These EVs are highly mobile owing to the stored electric power. With this mobility, an interesting concept, in which the stored power is used as a peak power shaver, has been proposed ${ }^{(1)-(3)}$. To achieve this, a PWM rectifier with a bidirectional dc-dc converter is used as a charger. The present authors, thus, have proposed a smart charger for EVs with a power quality compensator on single-phase three-wire distribution feeders ${ }^{(4)}$. The proposed smart charger consists of four-leg IGBTs. The first and second legs are connected to Feeder1 and Feeder2, respectively. The third leg is connected to the neutral line. This is an advantage of the previously proposed smart charger in comparison to the charger in Ref. (3). These three legs are used as a single-phase PWM rectifier, which converts power from ac to dc during the battery charging operation or from dc to ac during the battery discharging operation. This PWM rectifier can compensate for reactive and unbalanced active currents on single-phase three-wire distribution feeders by connecting the third leg to the neutral line. Simulation and experimental results have demonstrated that 
balanced source currents with a power factor of unity are obtained on the source side of single-phase three-wire distribution feeders during both the battery charging and discharging operations in EVs. When EVs are not connected to the proposed charger, the power quality is also improved on the secondary side of the pole-mounted distribution transformer.

For practical use, lower-priced chargers are needed. Reducing the capacity of the three-leg PWM rectifier, which performs as a smart charger, is effective to offer the smart charger as a commercial product. A source-side power factor of 0.9 is acceptable for home appliances in Japan according to the regulations ${ }^{(5)}$. Thus, controlling the reactive power on the source side is effective in reducing the capacity of the proposed smart charger. The present authors have proposed a method for reducing the required capacity of a three-leg structured PWM rectifier with reactive power control ${ }^{(6)}$. The correlation and cross-correlation coefficients between the source voltage and load currents are applied to define the fundamental active-reactive current in single-phase circuits. Going back by $T_{\mathrm{S}} / 4$ in the detected source voltage, the orthogonal component to the source voltage is generated, where $T_{\mathrm{S}}$ is the time period of the source voltage. The cross-correlation coefficient between the source voltage and the load current is calculated with this orthogonal component, and the reactive current of the load current is calculated with this cross-correlation coefficient. The proposed control algorithm with the correlation and cross-correlation coefficients requires many calculation steps. For practical use, a simple reactive-power control method is also required.

In this paper, we propose a new control algorithm for the previously proposed smart charger to reduce the capacity of the three-leg PWM rectifier, which performs as the smart charger, with reactive power control on the source side. A single-phase PLL in single-phase d-q coordinates is used to detect the phase angle of the source voltage. The in-phase and orthogonal components to the source voltage can be easily generated with the detected phase angle. Thus, the authors offer a simpler reactive-power control algorithm than that of Ref. (6). The basic principle of the proposed control algorithm is discussed in detail and then confirmed by a digital computer simulation using PSIM software. A prototype experimental model is also constructed and tested. The experimental results demonstrate that balanced source currents with a power factor of 0.9 , which is acceptable for Japanese home appliances, are achieved during both the battery charging and discharging operations in EVs. This reduces the capacity of the smart charger by $31 \%$ in comparison to that of the smart charger employing the previously proposed control algorithm.

Note that the charging or discharging power in both the simulation and experimental results is the same as that in Ref. (4). Thus, reducing the required capacity of the smart charger does not affect the battery charging and discharging capabilities.

\section{Reduction in Capacity of Smart Charger with Reactive Power Control}

Figure 1 shows a power circuit diagram of the previously proposed smart charger ${ }^{(4)}$. The rating of the pole-mounted distribution transformer is $6600 \mathrm{~V}_{\mathrm{rms}}, 5.0 \mathrm{kVA}$, and $60 \mathrm{~Hz}$ on the primary side, and $105 \mathrm{~V}_{\mathrm{rms}}$ and $24 \mathrm{~A}_{\mathrm{rms}}$ on the secondary side. The proposed smart charger consists of four-leg IGBTs. Three legs are used for a PWM rectifier, which converts power from ac to dc during the battery charging operation or from dc to ac during the battery discharging operation. One leg is connected to Feeder1, the second leg is connected to Feeder2, and the third leg is connected to the neutral line. This PWM rectifier can compensate for reactive and unbalanced active currents on single-phase three-wire distribution feeders by connecting the third leg to the neutral line. The fourth leg is used as a bidirectional dc-dc converter for both the battery charging and discharging operations in EVs.

Figure 2 shows a control circuit diagram of the newly proposed control algorithm for Fig. 1 with reactive power control on the source side. The basic principle of the proposed control algorithm is discussed here. Figure 3 shows a phasor diagram of the source voltage $v_{\mathrm{L}}$, source current $i_{\mathrm{S}}$, and load current $i_{\mathrm{L}} . \dot{V}_{\mathrm{L}}$ is the source voltage phasor, $\dot{I}_{\mathrm{L}}$ is the load current phasor, and $\dot{I}_{\mathrm{S}}$ is the source current phasor. $\dot{I}_{\mathrm{Lp}}$ is the active current phasor for $\dot{I}_{\mathrm{L}}$, and $\dot{I}_{\mathrm{Lq}}$ is the reactive current phasor for $\dot{I}_{\mathrm{L}}$. When balanced source currents with a power factor of unity are achieved, the smart charger supplies $\dot{I}_{\mathrm{SC}}^{\prime}$, which can perfectly compensate for the reactive current $\dot{I}_{\mathrm{Lq}}$. This perfect reactive current compensation requires a large-capacity smart charger. According to Japanese regulations ${ }^{(5)}$, a power factor of 0.9 is acceptable for home appliances. The sourceside power factor is 0.9 if only $K \dot{I}_{\mathrm{Lq}}$ is compensated, where $K=\left(I_{\mathrm{Lp}}+I_{\text {Sbat }}\right) \tan \left(\cos ^{-1} 0.9\right) / I_{\mathrm{Lq}}$. Then, the charger currents fed by the smart charger are $\dot{I}_{\mathrm{SC}}$, where balanced source currents with a power factor of 0.9 are obtained. Comparing $\dot{I}_{\text {SC }}^{\prime}$ with $\dot{I}_{\mathrm{SC}}$, it can be seen that controlling the fundamental reactive currents on the source side reduces the amplitudes of the charger currents of the smart charger. Thus, we can reduce the capacity of the smart charger. The required capacity of the smart charger with the proposed reactive power control will be shown in simulation and experimental results.

Let the primary-side voltage $v_{\mathrm{S}}$, secondary-side voltages $v_{\mathrm{L} 1}$ and $v_{\mathrm{L} 2}$, and load currents $i_{\mathrm{L} 1}$ and $i_{\mathrm{L} 2}$ be

$$
\begin{aligned}
& v_{\mathrm{S}}=\sqrt{2} V_{\mathrm{S}} \cos \omega_{\mathrm{S}} t, \\
& v_{\mathrm{L} 1}=v_{\mathrm{L} 2}=\sqrt{2} V_{\mathrm{L}} \cos \omega_{\mathrm{S}} t, \\
& i_{\mathrm{L} 1}=\sqrt{2} I_{\mathrm{L} 1} \cos \left(\omega_{\mathrm{S}} t-\phi_{\mathrm{L} 1}\right), \\
& i_{\mathrm{L} 2}=\sqrt{2} I_{\mathrm{L} 2} \cos \left(\omega_{\mathrm{S}} t-\phi_{\mathrm{L} 2}\right) .
\end{aligned}
$$

The source voltage $v_{\mathrm{S}}$ is detected, and then the phase angle $\theta_{\mathrm{S}}=\omega_{\mathrm{S}} t$ is generated by the single-phase PLL in singlephase $d$ - $q$ coordinates ${ }^{(7)(8)} \cdot \sqrt{2} \cos \omega_{\mathrm{S}} t$, which is in phase with $v_{\mathrm{S}}$, and $\sqrt{2} \sin \omega_{\mathrm{S}} t$, which is orthogonal to $v_{\mathrm{S}}$, are generated with $\theta_{\mathrm{S}}$. The generated $\sqrt{2} \cos \omega_{\mathrm{S}} t$ is multiplied by the load currents $i_{\mathrm{L} 1}$ and $i_{\mathrm{L} 2}$. Then,

$$
\begin{aligned}
\frac{1}{2}\left\{\left(i_{\mathrm{L} 1}+i_{\mathrm{L} 2}\right) \cdot \sqrt{2} \cos \omega_{\mathrm{S}} t\right\} \\
=\frac{1}{2}\left(I_{\mathrm{L} 1} \cos \phi_{\mathrm{L} 1}+I_{\mathrm{L} 2} \cos \phi_{\mathrm{L} 2}\right) \\
\quad+\frac{1}{2}\left\{I_{\mathrm{L} 1} \cos \left(2 \omega_{\mathrm{S}} t-\phi_{\mathrm{L} 1}\right)+I_{\mathrm{L} 2} \cos \left(2 \omega_{\mathrm{S}} t-\phi_{\mathrm{L} 2}\right)\right\} .
\end{aligned}
$$

$2 \omega_{\mathrm{S}}$ components are eliminated using a moving-average 


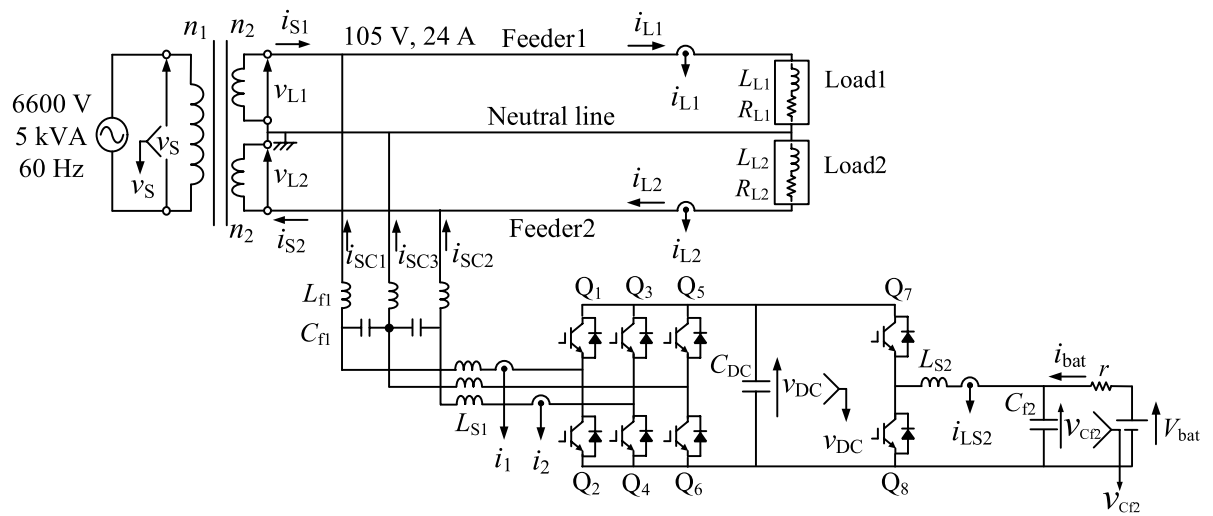

Fig. 1. Power circuit diagram of proposed smart charger for electric vehicles

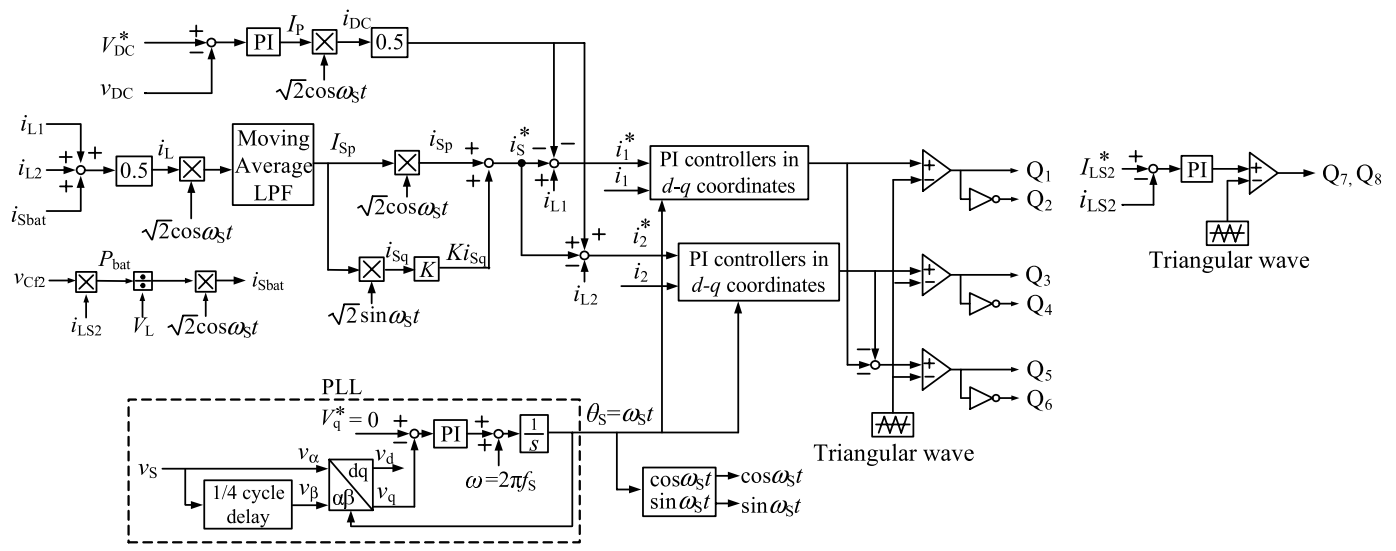

Fig. 2. New control circuit diagram of smart charger with reactive power control

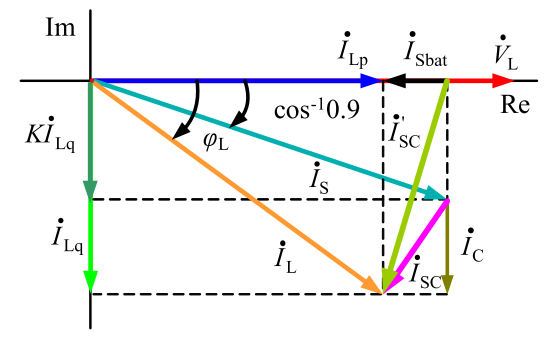

Fig. 3. Phasor diagram of source voltage, source current, and load current.

low-pass filter (LPF). The transfer function of the movingaverage LPF is expressed as

$$
H(z)=\frac{1}{N} \sum_{n=0}^{N-1} z^{-n},
$$

where $N$ is the number of samples. The dc component $I_{\mathrm{Lp}}$ is given as

$$
\begin{aligned}
I_{\mathrm{Lp}} & =\frac{1}{2} \overline{\left\{\left(i_{\mathrm{L} 1}+i_{\mathrm{L} 2}\right) \cdot \sqrt{2} \cos \omega_{\mathrm{S}} t\right\}} \\
& =\frac{1}{2}\left(I_{\mathrm{L} 1} \cos \phi_{\mathrm{L} 1}+I_{\mathrm{L} 2} \cos \phi_{\mathrm{L} 2}\right) .
\end{aligned}
$$

The dc component $I_{\mathrm{Lp}}$ corresponds to the mean active component for $i_{\mathrm{L} 1}$ and $i_{\mathrm{L} 2}$. Thus, the mean active current $i_{\mathrm{Lp}}$ for each load is expressed as

$$
i_{\mathrm{Lp}}=\sqrt{2} I_{\mathrm{Lp}} \cos \omega_{\mathrm{S}} t \text {. }
$$

The mean reactive component $I_{\mathrm{Lq}}$ of $i_{\mathrm{L} 1}$ and $i_{\mathrm{L} 2}$ with the generated $\sqrt{2} \sin \omega_{\mathrm{S}} t$ is also given by

$$
\begin{aligned}
I_{\mathrm{Lq}} & =\frac{1}{2} \overline{\left\{\left(i_{\mathrm{L} 1}+i_{\mathrm{L} 2}\right) \cdot \sqrt{2} \sin \omega_{\mathrm{S}} t\right\}} \\
& =\frac{1}{2}\left(I_{\mathrm{L} 1} \sin \phi_{\mathrm{L} 1}+I_{\mathrm{L} 2} \sin \phi_{\mathrm{L} 2}\right) .
\end{aligned}
$$

The mean reactive current $i_{\mathrm{Lq}}$ of $i_{\mathrm{L} 1}$ and $i_{\mathrm{L} 2}$ is expressed as

$$
i_{\mathrm{Lq}}=\sqrt{2} I_{\mathrm{Lq}} \sin \omega_{\mathrm{S}} t .
$$

Let the dc-side power that is from or to the battery be $P_{\text {bat }}$. $P_{\text {bat }}$ is expressed as

$$
P_{\text {bat }}=V_{\mathrm{Cf} 2} \cdot I_{\mathrm{LS} 2}
$$

where $V_{\mathrm{Cf} 2}$ is the mean value of $v_{\mathrm{Cf} 2}$ and $I_{\mathrm{LS} 2}$ is the mean value of $i_{\mathrm{LS} 2}$. The equivalent RMS value $I_{\text {Sbat }}$ on the source side, which is calculated from $P_{\text {bat }}$, is given by

$$
I_{\text {Sbat }}=\frac{P_{\text {bat }}}{V_{\mathrm{L}}}
$$

The total active current $i_{\text {Sbat }}$, which is given by $P_{\text {bat }}$, is expressed as

$$
\begin{aligned}
i_{\text {Sbat }} & =\sqrt{2} \frac{P_{\text {bat }}}{V_{\mathrm{L}}} \cos \omega_{\mathrm{S}} t \\
& =\sqrt{2} I_{\text {Sbat }} \cos \omega_{\mathrm{S}} t,
\end{aligned}
$$


Thus, the desired active current for each feeder on the source side is given by

$$
\begin{aligned}
i_{\text {Sp }} & =i_{\text {Lp }}+\frac{i_{\text {Sbat }}}{2} \\
& =\sqrt{2}\left(I_{\mathrm{Lp}}+\frac{I_{\text {Sbat }}}{2}\right) \cos \omega_{\mathrm{S}} t
\end{aligned}
$$

In Fig. 2, the sum of $i_{\mathrm{L} 1}, i_{\mathrm{L} 2}$ and $i_{\text {Sbat }}$ is calculated. Then, the generated sum is multiplied by the gain of 0.5 . A movingaverage $\mathrm{LPF}$ is used to calculate the active component $I_{\mathrm{Sp}}$, which is $I_{\mathrm{Lp}}+I_{\text {Sbat }} / 2$. The required reactive component $K i_{\mathrm{Sq}}$ is calculated with the power-factor-control gain of $K$ and the $i_{\text {Sq }}$, which multiples $I_{\text {Sp }}$ by $\sqrt{2} \sin \omega_{\mathrm{S}} t$. Thus, the desired source current $i_{\mathrm{S}}^{*}$ in both feeders, Feeder1 and Feeder2, is expressed as

$$
i_{\mathrm{S}}^{*}=\sqrt{2} I_{\mathrm{Sp}}\left\{\cos \omega_{\mathrm{S}} t+\tan \left(\cos ^{-1} 0.9\right) \sin \omega_{\mathrm{S}} t\right\} .
$$

The dc-capacitor voltage $v_{\mathrm{DC}}$ of the single-phase three-leg PWM rectifier is detected, and then the difference $\Delta v_{\text {DC }}$ between the reference value $V_{\mathrm{DC}}^{*}$ and the detected dc-capacitor voltage $v_{\mathrm{DC}}$ is amplified by a PI controller. The reference active component $i_{\mathrm{DC}}^{*}$ to control the dc-capacitor voltage $v_{\mathrm{DC}}$ is obtained by multiplying $I_{\mathrm{P}}$ by $\sqrt{2} \cos \omega_{\mathrm{S}} t$, which is calculated from $\theta_{\mathrm{S}}$. The reference values $i_{1}^{*}, i_{2}^{*}$, and $i_{3}^{*}$ for the smart charger are thus expressed as

$$
\begin{aligned}
& i_{1}^{*}=i_{\mathrm{L} 1}-i_{\mathrm{S}}^{*}-0.5 i_{\mathrm{DC}}^{*}, \\
& i_{2}^{*}=-i_{\mathrm{L} 2}+i_{\mathrm{S}}^{*}+0.5 i_{\mathrm{DC}}^{*}, \\
& i_{3}^{*}=-\left(i_{1}^{*}+i_{2}^{*}\right) .
\end{aligned}
$$

During the battery discharging operation of the circuit in Fig. 1, the power discharged from the batteries is automatically injected into the utility grid by constant dc-capacitor voltage control. During the battery charging operation, the power charged to the batteries is also automatically provided by the utility grid with constant dc-capacitor voltage control. In simulation and experimental results, which will be shown later, the power charged to and that discharged from the batteries are the same as those in Ref. (4). The authors claim that reducing the capacity of the smart charger with reactive power control does not affect the battery charging and discharging operations.

It is well known that a steady-state error remains when current feedback control based on the sine-triangle intercept technique with a PI controller is used. To avoid this error, an interesting current feedback control scheme in $d-q$ coordinates for single-phase circuits has been proposed ${ }^{(9)}$. Figure 4 shows a detailed block diagram of the single-phase current feedback control in $d-q$ coordinates in Fig. 2. The reference value $i_{1}^{*}$ is delayed by $T_{\mathrm{S}} / 4$ through the $T_{\mathrm{S}} / 4$ delay block. This reference value corresponds to the $\alpha$-phase reference value, and the reference value delayed by $T_{\mathrm{S}} / 4, i_{1 \beta}^{*}$, corresponds to the $\beta$-phase reference value. The detected output current $i_{1}$ of the first leg is detected. This detected current corresponds to the $\alpha$-phase current $i_{1}, i_{1}$ is also delayed by $T_{\mathrm{S}} / 4$. This delayed component corresponds to the $\beta$-phase

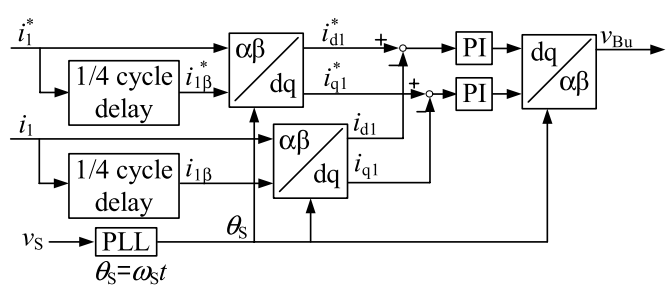

Fig. 4. Control circuit diagram of single-phase current feedback in $d$ - $q$ coordinates

current $i_{1 \beta}$. The differences between the reference values $i_{\mathrm{d} 1}^{*}$ and $i_{\mathrm{q} 1}^{*}$ and the detected values $i_{\mathrm{d} 1}$ and $i_{\mathrm{q} 1}$ are amplified by the PI controllers in $d$ - $q$ coordinates. The amplified differences are retransformed to $\alpha-\beta$ coordinates, and the sine-triangle intercept technique is used to control the output currents $i_{1}$ and $i_{2}$ Profs. Saitou and Shimizu proposed a novel current feedback control method in $d-q$ coordinates for single-phase circuits, in which a Hilbert transform is used ${ }^{(10)(11)}$. In their method, the Hilbert transform is implemented by numerical differentiation, which may result in instability in experimental systems. Thus, the feedback control in $d-q$ coordinates for single-phase circuits with a $T_{\mathrm{S}} / 4$ delay block is more feasible.

\section{Required Capacity of DC Capacitor}

From Ref. (13), the battery current ripple should be less than $5 \%$. The required capacity of the dc capacitor $C_{\mathrm{DC}}$ is discussed to ensure that the battery current ripple is less than $5 \%$ in the steady state. Here, the transfer function of the bidirectional dc-dc converter is derived to discuss the battery current ripple. It is well known that the transfer function of the bidirectional dc-dc converter can be derived using the state-space averaging method. Figure 5 shows an analysis circuit diagram of the bidirectional dc-dc converter. Let the state variables for the bidirectional dc-dc converter be $\boldsymbol{x}=\left[\begin{array}{ll}i_{\mathrm{LS} 2} & v_{\mathrm{Cf} 2}\end{array}\right]^{T}$. The state-space averaging equation and the output equation during the battery charging operation are given by

$$
\left\{\begin{aligned}
\frac{d \overline{\boldsymbol{x}}}{d t} & =\overline{\boldsymbol{A}} \overline{\boldsymbol{x}}+\overline{\boldsymbol{b}} v_{\mathrm{DC}} \\
i_{\mathrm{bat}} & =\overline{\boldsymbol{c}} \overline{\boldsymbol{x}}
\end{aligned}\right.
$$

where

$$
\begin{aligned}
& \overline{\boldsymbol{A}}=\left[\begin{array}{cc}
0 & \frac{1}{L_{\mathrm{S} 2}} \\
-\frac{1}{C_{\mathrm{f} 2}} & -\frac{1}{r C_{\mathrm{f} 2}}
\end{array}\right], \quad \overline{\boldsymbol{b}}=\left[\begin{array}{c}
-\frac{D}{L_{\mathrm{S} 2}} \\
0
\end{array}\right], \\
& \overline{\boldsymbol{c}}=\left[\begin{array}{ll}
0 & -\frac{1}{r}
\end{array}\right],
\end{aligned}
$$

and $D=V_{\text {bat }} / V_{\mathrm{DC}}$. The transfer function $G_{1}(s)$ between $I_{\text {bat }}(s)$ and $V_{\mathrm{DC}}(s)$ during the battery charging operation is expressed as

$$
G_{1}(s)=\frac{I_{\mathrm{bat}}(s)}{V_{\mathrm{DC}}(s)}=\overline{\boldsymbol{c}}(s I-\overline{\boldsymbol{A}})^{-1} \overline{\boldsymbol{b}}
$$

Thus, $G_{1}(s)$ is given by

$$
G_{1}(s)=\frac{\frac{D}{r L_{\mathrm{S} 2} C_{\mathrm{f} 2}}}{s^{2}+\frac{s}{r C_{\mathrm{f} 2}}+\frac{1}{L_{\mathrm{S} 2} C_{\mathrm{f} 2}}}
$$




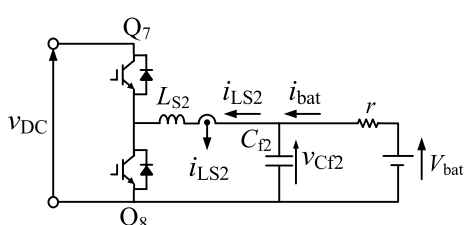

Fig. 5. Analysis circuit diagram of the bidirectional dcdc converter

For the battery discharging operation,

$$
\begin{aligned}
& \overline{\boldsymbol{A}}=\left[\begin{array}{cc}
0 & \frac{1}{L_{\mathrm{S} 2}} \\
-\frac{1}{C_{\mathrm{f} 2}} & -\frac{1}{r C_{\mathrm{f} 2}}
\end{array}\right], \quad \overline{\boldsymbol{b}}=\left[\begin{array}{c}
-\frac{1-D}{L_{\mathrm{S} 2}} \\
0
\end{array}\right], \\
& \overline{\boldsymbol{c}}=\left[\begin{array}{ll}
0 & -\frac{1}{r}
\end{array}\right] .
\end{aligned}
$$

The transfer function $G_{2}(s)$ during the battery discharging operation is given by

$$
G_{2}(s)=\frac{\frac{1-D}{r L_{\mathrm{S} 2} C_{\mathrm{f} 2}}}{s^{2}+\frac{s}{r C_{\mathrm{f} 2}}+\frac{1}{L_{\mathrm{S} 2} C_{\mathrm{f} 2}}}
$$

The absolute value $\left\|G_{1}\left(j 2 \omega_{\mathrm{S}}\right)\right\|$ for the $2 \omega_{\mathrm{S}}$ component, where $\omega_{\mathrm{S}}$ is the angular frequency of the source voltage $v_{\mathrm{S}}$, is 0.376 , while $\left\|G_{2}\left(j 2 \omega_{\mathrm{S}}\right)\right\|$ is 0.0261 .

The inverse of the absolute value $\left\|G_{2}\left(j 2 \omega_{\mathrm{S}}\right)\right\|$ is larger than that of $\left\|G_{1}\left(j 2 \omega_{\mathrm{S}}\right)\right\|$ for the $2 \omega_{\mathrm{S}}$ component. The allowed ripple ratio of the dc-capacitor voltage $v_{\mathrm{DC}}$ is discussed with the inverse of 0.0261. From Ref. (13), the ripple current amplitude of $i_{\text {bat }}$ should be less than $0.25 \mathrm{~A}$ when the mean value of the battery current $\bar{i}_{\text {bat }}$ is $5 \mathrm{~A}$. The allowed fluctuation voltage $\tilde{v}_{\mathrm{DC}}$ is $9.58 \mathrm{~V}$. In the following simulation and experimental results, the mean value of the dc-capacitor voltage $\bar{v}_{\mathrm{DC}}$ is $385 \mathrm{~V}$. The allowed ripple ratio of the dc-capacitor voltage $v_{\text {DC }}$ is less than $2.5 \%$. The required capacity of the dc capacitor $C_{\mathrm{DC}}$ with a ripple ratio of $2.5 \%$ is discussed considering the instantaneous power flows into $C_{\mathrm{DC}}$. The instantaneous power $p_{\mathrm{C}}$ flowing into the three-leg rectifier is given by

$$
\begin{aligned}
p_{\mathrm{C}}= & -v_{\mathrm{L} 1} \cdot i_{\mathrm{SC} 1}+v_{\mathrm{L} 2} \cdot i_{\mathrm{SC} 2} \\
= & -P_{\mathrm{bat}}-P_{\mathrm{bat}} \cos 2 \omega_{\mathrm{S}} t \\
& -P_{\mathrm{r}} \sin 2 \omega_{\mathrm{S}} t,
\end{aligned}
$$

where

$$
\begin{aligned}
& P_{\mathrm{bat}}=V_{\mathrm{L}}\left(I_{\mathrm{L} 1} \cos \phi_{\mathrm{L} 1}+I_{\mathrm{L} 2} \cos \phi_{\mathrm{L} 2}-2 I_{\mathrm{Sp}}\right), \\
& P_{\mathrm{r}}=V_{\mathrm{L}}\left(I_{\mathrm{L} 1} \sin \phi_{\mathrm{L} 1}+I_{\mathrm{L} 2} \sin \phi_{\mathrm{L} 2}-2 K I_{\mathrm{Sp}}\right) .
\end{aligned}
$$

In Eq. (18), the ac component $\tilde{p}_{\mathrm{C}}$ of $p_{\mathrm{C}}$ is written as

$$
\tilde{p}_{\mathrm{C}}=-P \cos \left(2 \omega_{\mathrm{S}} t-\phi_{\mathrm{p}}\right),
$$

where

$$
P=\sqrt{P_{\mathrm{bat}}^{2}+P_{\mathrm{r}}^{2}}, \phi_{\mathrm{p}}=\tan ^{-1} \frac{P_{\mathrm{r}}}{P_{\mathrm{bat}}} .
$$

Figure 6 shows the schematic waveforms for $v_{\mathrm{DC}}$ and $\tilde{p}_{\mathrm{C}}$ during the battery charging operation. If $v_{\mathrm{DC}}$ is increased, $\tilde{p}_{\mathrm{C}}$ is

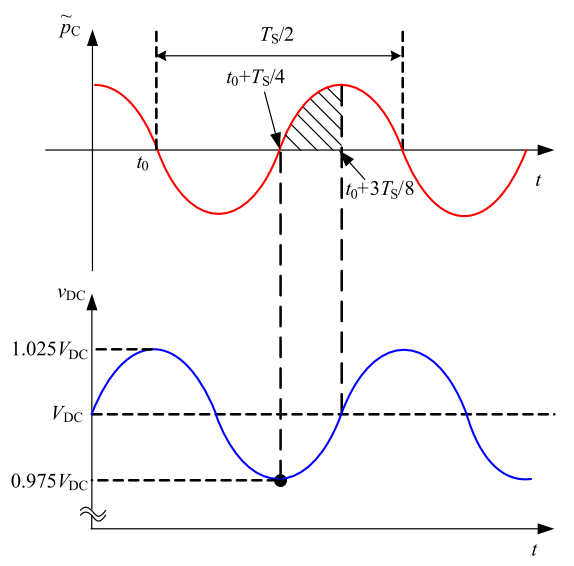

Fig. 6. Schematic waveforms for $v_{\mathrm{DC}}$ and $\tilde{p}_{\mathrm{C}}$ during battery charging operation

increased from $t_{0}+T_{\mathrm{S}} / 4$ to $t_{0}+3 T_{\mathrm{S}} / 8$, where the initial value $t_{0}$ is $\phi_{\mathrm{p}} / 2 \omega_{\mathrm{S}}$. $V_{\mathrm{DC}}$ is the mean value of $v_{\mathrm{DC}}$. The fluctuation ratio of $v_{\mathrm{DC}}$ is $2.5 \%$ in the steady state; then, the following equation is obtained:

$$
\begin{aligned}
& \int_{t_{0}+T_{\mathrm{S}} / 4}^{t_{0}+3 T_{\mathrm{S}} / 8} \tilde{p}_{\mathrm{C}} d t \\
& \quad=\frac{1}{2} C_{\mathrm{DC}}\left\{V_{\mathrm{DC}}^{2}-\left(0.975 V_{\mathrm{DC}}\right)^{2}\right\} .
\end{aligned}
$$

From Eq. (20), if $v_{\mathrm{DC}}$ is decreased, the following formula is obtained :

$$
\begin{aligned}
& \int_{t_{0}+T_{\mathrm{S}} / 8}^{t_{0}+T_{\mathrm{S}} / 4} \tilde{p}_{\mathrm{C}} d t \\
& \quad=\frac{1}{2} C_{\mathrm{DC}}\left\{\left(0.975 V_{\mathrm{DC}}\right)^{2}-V_{\mathrm{DC}}^{2}\right\},
\end{aligned}
$$

where $\tilde{p}_{\mathrm{C}}$ is decreased from $t_{0}+T_{\mathrm{S}} / 8$ to $t_{0}+T_{\mathrm{S}} / 4$. From Eqs. (20) and (21), the fluctuation voltage amplitude of $v_{\mathrm{DC}}$ is $0.025 V_{\mathrm{DC}}$, which is expressed as

$$
0.025 V_{\mathrm{DC}}=\frac{P}{1.975 \omega_{\mathrm{S}} C_{\mathrm{DC}} V_{\mathrm{DC}}}
$$

The RMS value $I_{0}$ of the fluctuation current flowing to $C_{\mathrm{DC}}$ is given by

$$
I_{0}=\frac{\frac{0.025 V_{\mathrm{DC}}}{\sqrt{2}}}{X_{\mathrm{C}}}=\frac{\sqrt{2} P}{1.975 V_{\mathrm{DC}}}, \cdots
$$

where $X_{\mathrm{C}}=1 / 2 \omega_{\mathrm{S}} C_{\mathrm{DC}}$. From Eq. (20) to Eq. (22), $I_{0}$ is determined to be $4.17 \mathrm{~A}_{\mathrm{rms}}$. From Ref. (12), the required capacity of $C_{\mathrm{DC}}$ is set to $1200 \mu \mathrm{F}$ in the steady state.

The dc-capacitor voltage fluctuations in the transient state are caused by the load variations. These fluctuations also occur after the charging or discharging operation is started or stopped. The dc-capacitor voltage fluctuations caused by the load variations are larger than those caused by the steady state. Thus, the dc-capacitor voltage fluctuations caused by the load variations are considered here. In the constructed experimental model, as shown later, the maximum dc-capacitor voltage $v_{\mathrm{DC}}$ is less than $400 \mathrm{~V}$, while the mean value of the 
dc-capacitor voltage is $385 \mathrm{~V}$. Only $\Delta V_{\mathrm{DC}}=15 \mathrm{~V}$ is allowed in the transient state when the load conditions are varied. The authors have confirmed by simulation that the fluctuation $\Delta V_{\mathrm{DC}}$ is less than $15 \mathrm{~V}$ in the transient state when the load varies from heavy load to light load with a dc-capacitor $C_{\mathrm{DC}}$ of capacity $2200 \mu \mathrm{F}$. Thus, a dc capacitor $C_{\mathrm{DC}}$ of capacity $2200 \mu \mathrm{F}$ is used in the following simulations and experiments. Typical simulation and experimental results will be shown later.

\section{Simulation Results}

A digital computer simulation using PSIM software was carried out to confirm the validity and high feasibility of the proposed control algorithm. Table 1 shows the constants for Fig. 1 that are used in the following simulation and experimental verifications. In the simulation results, the battery voltage $V_{\text {bat }}$ is $360 \mathrm{~V}$, which is used in the Nissan LEAF. The rating of the distribution transformer is $6600 \mathrm{~V}_{\mathrm{rms}}, 5.0 \mathrm{kVA}$, and $60 \mathrm{~Hz}$ on the primary side, and $105 \mathrm{~V}_{\mathrm{rms}}$ and $24 \mathrm{~A}_{\mathrm{rms}}$ on the secondary side. The unbalanced ratio between Feeder 1 and Feeder 2 is defined by

$$
\text { Unbalanced ratio }=\frac{\mathrm{S}_{1}-\mathrm{S}_{2}}{\mathrm{~S}_{\mathrm{A}} \times 0.5} \times 100[\%], \cdots \cdots
$$

where $S_{1}$ is the apparent power of Load1 on Feeder1 and $S_{2}$ is the apparent power of Load2 on Feeder2. $S_{\mathrm{A}}$ is the total apparent power, which is the sum of the apparent powers $S_{1}$ and $S_{2}$ on Feeder1 and Feeder2, respectively. According to Japanese guidelines for the domestic use of power, the unbalanced ratio should be less than $40 \%{ }^{(14)}$. Thus, an RL load of 1.2 pu with a power factor of 0.8 is connected to Feeder 1 and an RL load of 0.8 pu with a power factor of 0.9 is connected to Feeder2, as shown in Fig. 1, so that the unbalanced ratio given by Eq. (24) is $40 \% . K_{\mathrm{P}}=0.3$ and $T_{\mathrm{I}}=0.02 \mathrm{~s}$ were used in the PI controller for constant dc-capacitor voltage control in both the simulation and experiment. $K_{\mathrm{P}}=0.05$ and $T_{\mathrm{I}}=8 \mathrm{~ms}$ were used in the PI controller for current feedback control in $d$ - $q$ coordinates in the single-phase circuits. The reference value $V_{\mathrm{DC}}^{*}$ for the dc-capacitor voltage of the three-leg PWM rectifier was $385 \mathrm{~V}$.

Figure 7 shows the simulation results for Fig. 1, where the proposed smart charger is under the battery charging operation with constant battery current control. Although the load currents $i_{\mathrm{L} 1}$ and $i_{\mathrm{L} 2}$ are unbalanced, the source currents $i_{\mathrm{S} 1}$ and $i_{\mathrm{S} 2}$ are balanced with a power factor of 0.9. As stated previously, the ripple of the battery current $i_{\text {bat }}$ should be less than $\pm 5 \%{ }^{(13)}$. From the simulation results in Fig. 7, the ripple of the battery current is approximately $3.47 \%$.

The total harmonic distortion (THD) is defined as

$$
\mathrm{THD}=\frac{\sqrt{\sum_{n=2}^{\infty} I_{n}^{2}}}{I_{1}} \times 100[\%] . \cdots \ldots \ldots \ldots \ldots \ldots
$$

The THDs of $i_{\mathrm{S} 1}$ and $i_{\mathrm{S} 2}$ calculated from Fig. 7 are $1.54 \%$ and $0.89 \%$, respectively. These values satisfy the guidelines ${ }^{(15)}$.

Figure 8 shows the simulation results for Fig. 1, where the proposed smart charger is under the battery discharging operation with constant battery current control. Although the load currents $i_{\mathrm{L} 1}$ and $i_{\mathrm{L} 2}$ are unbalanced, the source currents $i_{\mathrm{S} 1}$
Table 1. Circuit Constants for Fig. 1

\begin{tabular}{c|c|c}
\hline Item & Symbol & Value \\
\hline \hline $\begin{array}{c}\text { Load1 } \\
(1.2 \text { pu, Power factor 0.8) }\end{array}$ & $L_{\mathrm{L} 1}$ & $5.8 \mathrm{mH}$ \\
\cline { 2 - 3 }$\left(\begin{array}{c}\text { Load2 } \\
\text { (0.8 pu, Power factor 0.9) }\end{array}\right.$ & $R_{\mathrm{L} 2}$ & $6.9 \Omega$ \\
\cline { 2 - 3 } & $R_{\mathrm{L} 2}$ & $4.9 \Omega$ \\
\hline Filter inductor & $L_{\mathrm{f} 1}$ & $0.46 \mathrm{mH}$ \\
\hline Filter capacitor & $C_{\mathrm{f} 1}$ & $10.4 \mu \mathrm{F}$ \\
\hline $\begin{array}{c}\text { Switching inductor for } \\
\text { three-leg inverter }\end{array}$ & $L_{\mathrm{S} 1}$ & $1.0 \mathrm{mH}$ \\
\hline DC capacitor & $C_{\mathrm{DC}}$ & $2200 \mu \mathrm{F}$ \\
\hline DC-capacitor voltage & $V_{\mathrm{DC}}^{*}$ & $385 \mathrm{~V}$ \\
\hline $\begin{array}{c}\text { Switching inductor for } \\
\text { dc-dc converter }\end{array}$ & $L_{\mathrm{S} 2}$ & $3.3 \mathrm{mH}$ \\
\hline $\begin{array}{c}\text { Filter capacitor for } \\
\text { dc-dc converter }\end{array}$ & $C_{\mathrm{f} 2}$ & $1000 \mu \mathrm{F}$ \\
\hline Battery current & $I_{\mathrm{LS} 2}^{*}$ & $5 \mathrm{~A}$ \\
\hline Internal resistance of battery & $r$ & $72 \mathrm{~m} \Omega$ \\
\hline Switching frequency & $f_{\mathrm{SW}}$ & $12 \mathrm{kHz}$ \\
\hline Dead time & $T_{\mathrm{d}}$ & $3.5 \mu \mathrm{s}$ \\
\hline
\end{tabular}

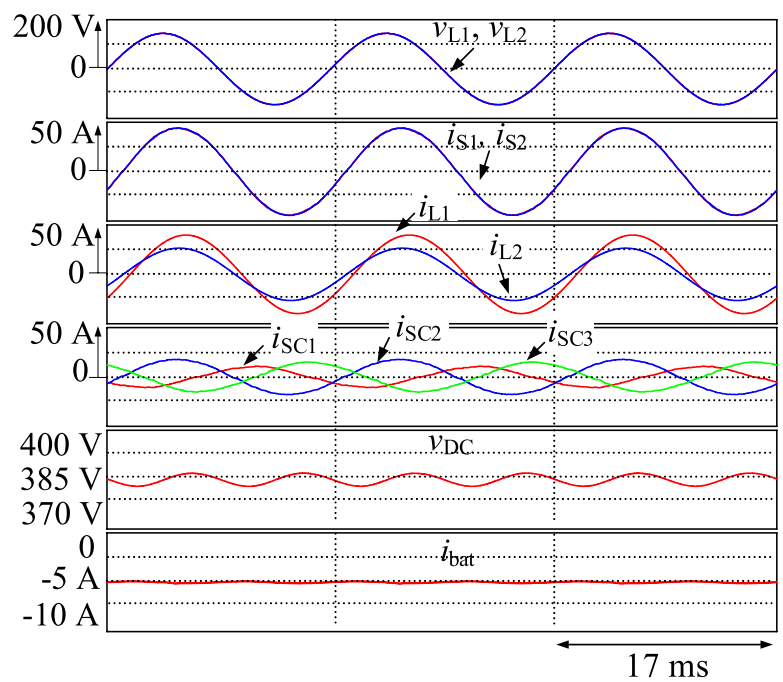

Fig. 7. Simulation waveforms for Fig. 1 during battery charging operation

and $i_{\mathrm{S} 2}$ are balanced with a power factor of 0.9 . The ripple of $i_{\text {bat }}$ is $3.59 \%$. The THDs of $i_{\mathrm{S} 1}$ and $i_{\mathrm{S} 2}$ are $1.63 \%$ and $2.84 \%$, respectively. These values also satisfy the guidelines ${ }^{(15)}$.

The required capacity of the three-leg PWM rectifier, which performs as a smart charger, is now discussed. A definition of apparent power is generally used to calculate the required capacity of the PWM rectifier. However, the third leg that is connected to the neutral line is grounded. The definition of the usually used apparent power is not applicable to the three-leg PWM rectifier. This means that the capacity of the third leg is zero. If the third-leg capacity is calculated with the feeder voltage $V_{\mathrm{L}}$, the required capacity $S_{\mathrm{C}}$ of the three-leg PWM rectifier is expressed as

$$
S_{\mathrm{C}}=\frac{V_{\mathrm{L}}\left(\sum_{n=1}^{3} I_{\mathrm{SCn}}\right)}{2 V_{\mathrm{L}} \cdot I_{\mathrm{A}}}[\mathrm{pu}],
$$

where $I_{\mathrm{SCn}}$ is the RMS value of the output currents of the three-leg PWM rectifier, and $I_{\mathrm{A}}$ is the RMS value of the rating current for each feeder. Thus, the authors propose a current capacity for the PWM rectifier with a three-leg topology. A current capacity $A_{\mathrm{C}}$ for a three-leg PWM rectifier is defined 


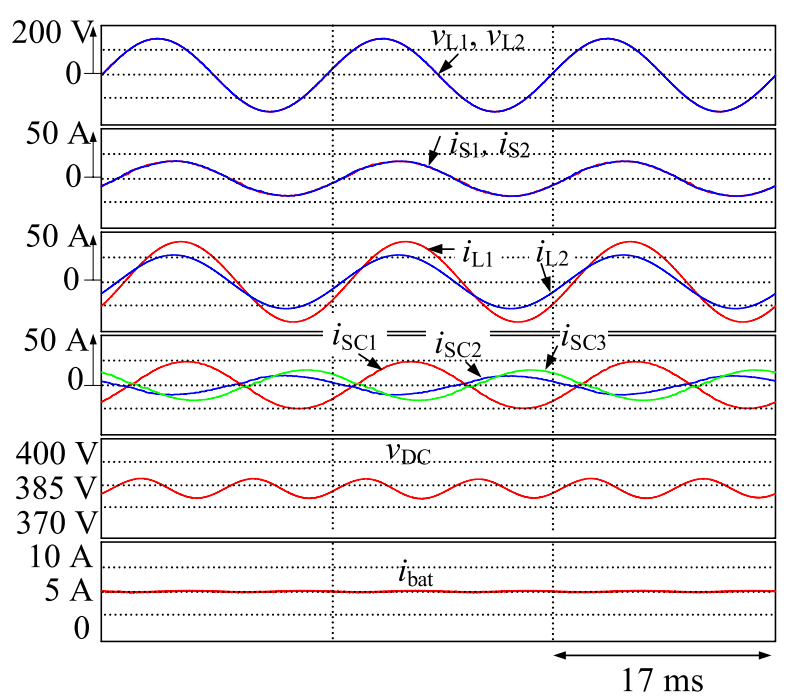

Fig. 8. Simulation waveforms for Fig. 1 during battery discharging operation

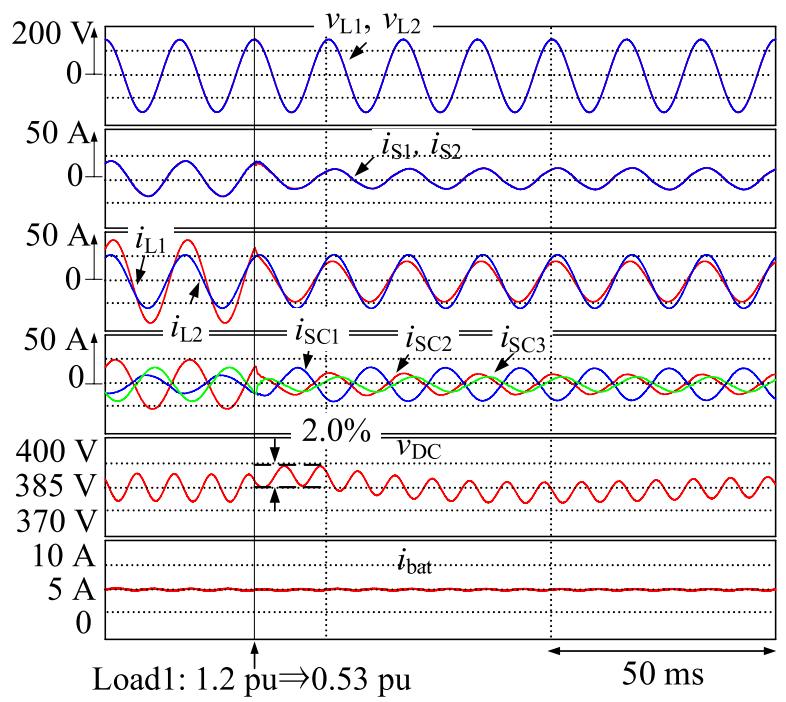

Fig. 9. Simulation waveforms for Fig. 1 with the load variation of Load1 during battery discharging operation

as

$$
A_{\mathrm{C}}=\frac{\sum_{n=1}^{3} I_{\mathrm{SCn}}}{2 I_{\mathrm{A}}}[\mathrm{pu}] .
$$

From Figs. 7 and $8, A_{\mathrm{C}}$ is $0.71 \mathrm{pu}$. On the other hand, in the simulation results in Ref. (4), the required current capacity of the smart charger is $0.97 \mathrm{pu}$. We can thus reduce the capacity of the smart charger by $27 \%$ using the proposed control algorithm with reactive power control on the source side in comparison to using the previously proposed control algorithm.

Figure 9 shows simulation results for Fig. 1 with the load variation of Load1 during the battery discharging operation. Load2 is kept constant, and Load1 is varied from 1.2 pu to $0.53 \mathrm{pu}$ with an unbalanced ratio of $40 \%$. Before and after Load1 was varied, the source currents $i_{\mathrm{S} 1}$ and $i_{\mathrm{S} 2}$ are balanced with a power factor of 0.9 during the battery discharging operation. The dc-capacitor voltage fluctuation $\Delta V_{\mathrm{DC}}$ is less

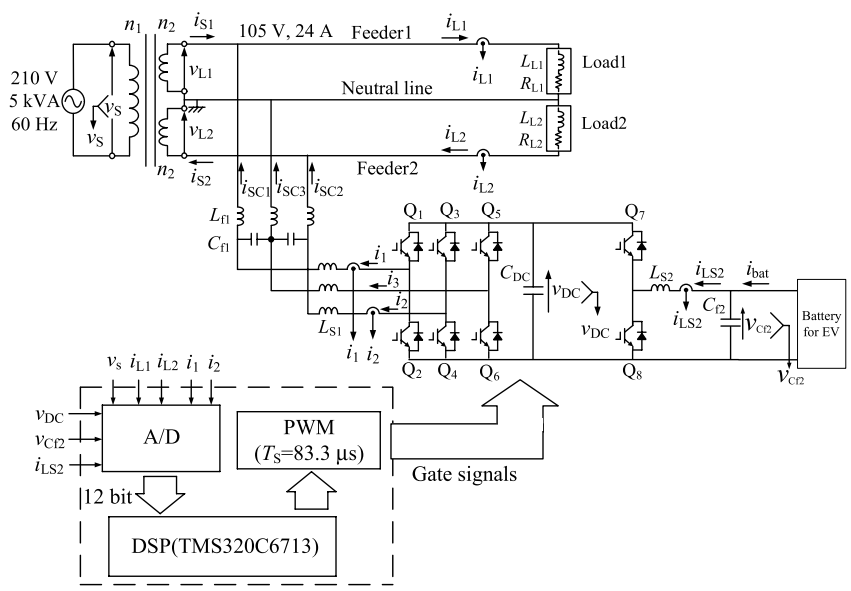

Fig. 10. Block diagram of constructed experimental model for smart charger in Fig. 1 with proposed control strategy.

than $15 \mathrm{~V}$. Thus, using a dc capacitor $C_{\mathrm{DC}}$ of $2200 \mu \mathrm{F}$ is sufficient to ensure the battery current ripple, which should be less than $5 \%$.

\section{Experimental Results}

It is difficult to construct an experimental model with the actual voltage rating of the pole-mounted distribution transformer for the smart charger of Fig. 1 in the laboratory. A reduced-scale experimental model was thus constructed and tested to demonstrate the validity and high applicability of the proposed control method, which involves reactive power control. Figure 10 shows a block diagram of the constructed prototype experimental model. Figure 11 shows the battery model for Fig. 10. The rating of the pole-mounted distribution transformer is $210 \mathrm{~V}_{\mathrm{rms}}, 5.0 \mathrm{kVA}$, and $60 \mathrm{~Hz}$ on the primary side, and $105 \mathrm{~V}_{\mathrm{rms}}$ and $24 \mathrm{~A}_{\mathrm{rms}}$ on the secondary side. The charged power is consumed by a $60 \Omega$ resistor $R$, which is connected in parallel to capacitor $C_{\mathrm{f} 2}$, during the battery charging operation. For the battery discharging operation, a dc supply power (Takasago: HX0300-25) with an internal resistor $r$ of $72 \mathrm{~m} \Omega$ is connected to $C_{\mathrm{f} 2}$. The maximum voltage of HX0300-25 is $300 \mathrm{~V}$. In the experimental results of Figs. 13 and 14, $V_{\text {bat }}$ was $300 \mathrm{~V}$ as shown in Fig. 11(b). The detected primary-side voltage $v_{\mathrm{S}}$, load currents $i_{\mathrm{L} 1}$ and $i_{\mathrm{L} 2}$, charger currents $i_{1}$ and $i_{2}$, and dc-capacitor voltage $v_{\mathrm{DC}}$ are fed into a digital signal processor (DSP) (TMS320C6713, $225 \mathrm{MHz}$ ) through 12-b A/D converters, where the sampling time $T_{\mathrm{S}}$ is $83.3 \mu \mathrm{s}$. In the DSP, the reference values $i_{1}^{*}, i_{2}^{*}$, and $i_{3}^{*}$ for the three-leg PWM rectifier, which acts as a power quality compensator, are calculated with Eq. (13). The battery voltage $v_{\mathrm{Cf} 2}$ and battery current $i_{\mathrm{LS} 2}$ of the bidirectional $\mathrm{dc}-\mathrm{dc}$ converter are also fed into the DSP through 12-b A/D converters. The feedback control in $d$ - $q$ coordinates is used for the single-phase circuits in Fig. 4. This current feedback control was carried out in the DSP. $K_{\mathrm{P}}=0.3$ and $T_{\mathrm{I}}=0.02 \mathrm{~s}$ were used in the PI controller for constant dc-capacitor voltage control in the experiment. $K_{\mathrm{P}}=0.05$ and $T_{\mathrm{I}}=8 \mathrm{~ms}$ were used in the PI controller for current feedback control in $d-q$ coordinates for the single-phase circuits.

Figure 12 shows the experimental results for the experimental model in Fig. 10, where the proposed smart charger 


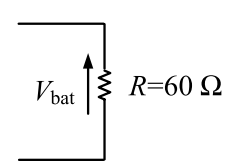

(a) Battery charging operation

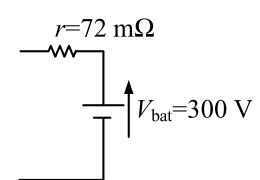

(b) Battery discharging operation
Fig. 11. Battery for EV with the experimental setup shown in Fig. 10 during each battery operation

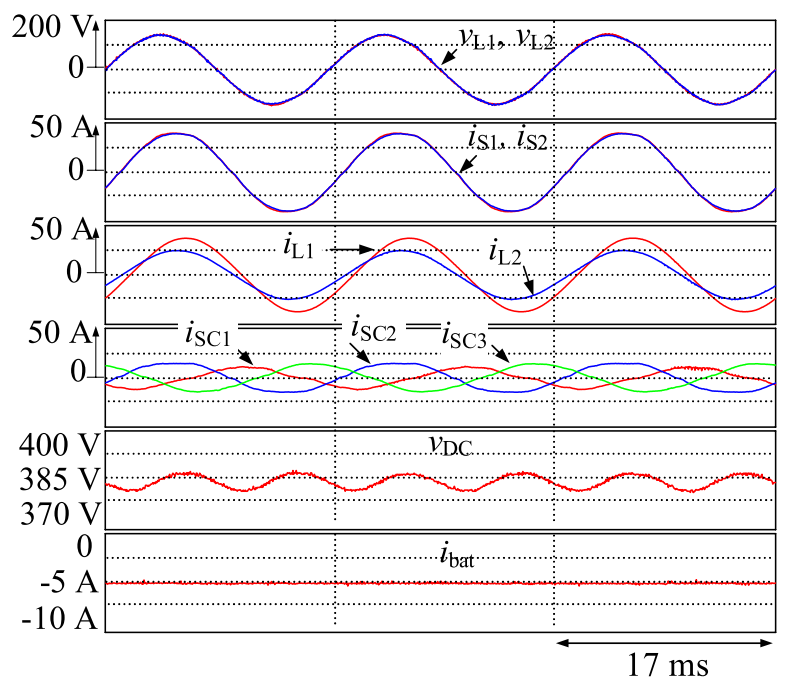

Fig. 12. Experimental waveforms for experimental model in Fig. 10 during battery charging operation

was under a battery charging operation with constant battery current control. Although the load currents $i_{\mathrm{L} 1}$ and $i_{\mathrm{L} 2}$ are unbalanced, the source currents $i_{\mathrm{S} 1}$ and $i_{\mathrm{S} 2}$ are balanced with a power factor of 0.9 during the charging of the batteries in the EV. The ripple of $i_{\text {bat }}$ is $2.38 \%$. The THDs of $i_{\mathrm{S} 1}$ and $i_{\mathrm{S} 2}$ calculated from Fig. 10 are $1.68 \%$ and $1.66 \%$.

Figure 13 shows the experimental results for the experimental model in Fig. 10, where the proposed smart charger was under a battery discharging operation with constant battery current control. Although the load currents $i_{\mathrm{L} 1}$ and $i_{\mathrm{L} 2}$ are unbalanced, the source currents $i_{\mathrm{S} 1}$ and $i_{\mathrm{S} 2}$ are balanced with a power factor of 0.9 during the discharging of the batteries in the EV. The ripple of $i_{\text {bat }}$ is $3.36 \%$. The THDs of $i_{\mathrm{S} 1}$ and $i_{\mathrm{S} 2}$ are $4.50 \%$, and $4.31 \%$, respectively. In Fig. 13, $A_{\mathrm{C}}$ is $0.66 \mathrm{pu}$. In the experimental results in Ref. (4), the capacity of the smart charger is $0.96 \mathrm{pu}$. Therefore, controlling the power factor to 0.9 on the source side can reduce the capacity of the smart charger with the newly proposed control algorithm by $31 \%$ in comparison to that of the smart charger with the previously proposed control algorithm ${ }^{(4)}$.

Figure 14 shows experimental results for the experimental model in Fig. 10 with the load variation of Load 1 during the battery discharging operation. Load2 is kept constant, and Load1 is varied from $1.2 \mathrm{pu}$ to $0.53 \mathrm{pu}$ with an unbalanced ratio of $40 \%$. Before and after Load1 was varied, the source currents $i_{\mathrm{S} 1}$ and $i_{\mathrm{S} 2}$ are balanced with a power factor of 0.9 during the battery discharging operation. The dc-capacitor voltage fluctuation $\Delta V_{\mathrm{DC}}$ is less than $15 \mathrm{~V}$. Thus, using a dc capacitor $C_{\mathrm{DC}}$ of $2200 \mu \mathrm{F}$ is sufficient to ensure the battery current ripple, which should be less than $5 \%$. These experimental results in Figs. 12, 13, and 14 agree well with the

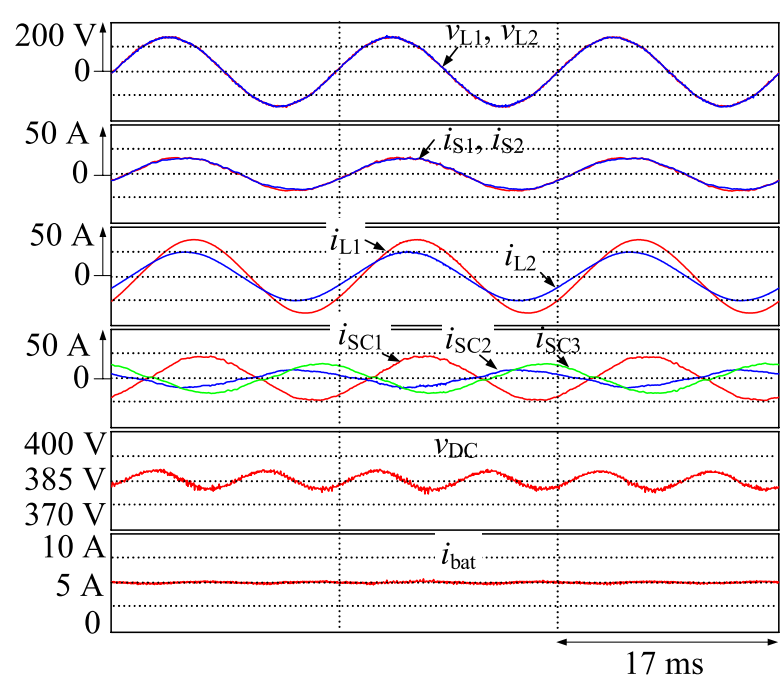

Fig. 13. Experimental waveforms for the experimental model in Fig. 10 during battery discharging operation

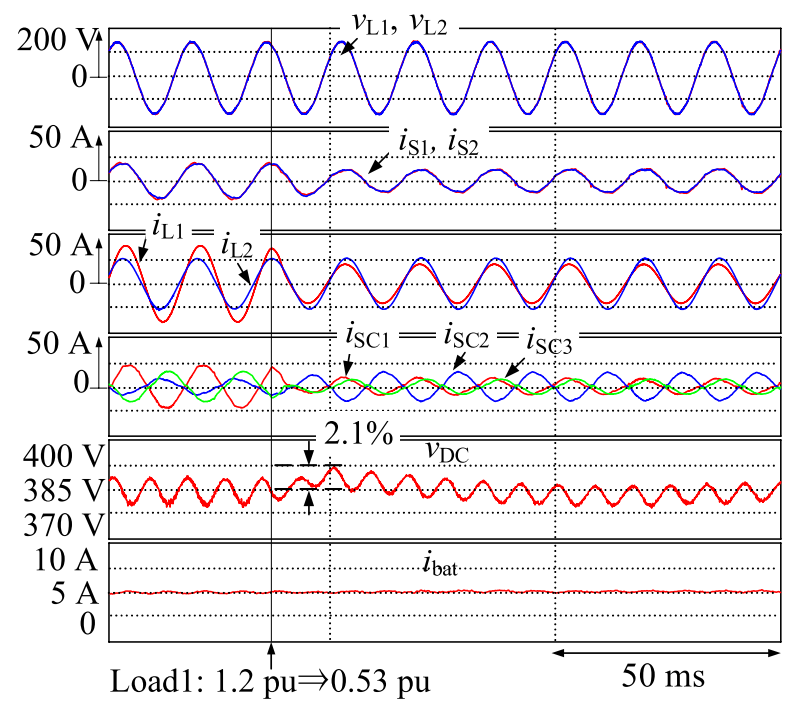

Fig. 14. Experimental waveforms for the experimental model in Fig. 10 with the load variation of Load1 during battery discharging operation

simulation results in Figs. 7, 8, and 9.

Note that the charging or discharging power in both the simulation and experimental results is the same as that in Ref. (4). Thus, reducing the capacity of the smart charger does not affect the battery charging and discharging capabilities.

\section{Conclusion}

In this paper, we have proposed a new control algorithm for reducing the capacity of the previously proposed smart charger with reactive power control. The smart charger consists of four-leg structured IGBTs. The three-leg structure topology is used for a single-phase PWM rectifier, where two legs are connected to each feeder and the third leg is connected to the neutral line. This PWM rectifier can compensate for reactive and unbalanced active currents on singlephase three-wire distribution feeders. The fourth leg is used as a bidirectional dc-dc converter for battery charging and discharging operations. The authors have shown theoretically 
that controlling the reactive power on the source side can reduce the capacity of the previously proposed smart charger. The basic principle of the proposed control algorithm was discussed in detail and was then verified with a digital computer simulation using PSIM software. A reduced-scale experimental model was also constructed and tested. The experimental results demonstrated that balanced source currents with a power factor of 0.9 are achieved on the secondary side of the single-phase three-wire feeders during both battery charging and discharging operations in EVs. This reduces the capacity of the smart charger with the newly proposed control algorithm by $31 \%$ in comparison to that of the smart charger with the previously proposed control algorithm. When EVs are not connected to the proposed smart charger, the power quality is also compensated on the secondary side of the polemounted distribution transformer. Reducing the capacity of the smart charger does not affect the battery charging and discharging operations as shown in both the simulation and experimental results. Thus, it is concluded that the proposed charger with the new control algorithm is useful for practical applications.

\section{References}

( 1 ) Y. Mitani: "Method and System for Leveling Power Load", Japan Patent Office, P2007-282383A (2007)

(2) NISSAN Official web site http://www.nissan-global/com/JP/NEWS/

( 3 ) M.C. Kisacikoglu, B. Ozpineci, and L.M. Tolbert: "Reactive Power Operation Analysis of a Single-Phase EV/PHEV Bidirectional Battery Charger", in Proc. of Int. Conf. Power Electron.-ECCE Asia, pp.585-591 (2011)

( 4 ) T. Tanaka, T. Sekiya, H. Tanaka, E. Hiraki, and M. Okamoto: "Smart Charger for Electric Vehicles with Power Quality Compensator on Single-Phase Three-Wire Distribution Feeders", IEEE Trans. IA, Vol.49, No.6, pp.26282635 (2013)

( 5 ) The Chugoku Electric Power Co., Inc: "Electric-Supply Stipulation", p.46 (2012) (in Japanese)

( 6 ) H. Fukui, E. Hiraki, T. Tanaka, and S. Fukuma: "A New Control Method of Current Balancer for Single-Phase Three-Wire Secondary Distribution Systems Using the Correlation and Cross-Correlation Coefficients", IEEJ Trans. IA, Vol.128, No.1, pp.34-40 (2008)

( 7 ) L.N. Arruda, S.M. Silva, and B.J.C. Filho: "PLL Structures for Utility Connected Systems", in Conf. Record of IEEE-IAS Annual Meeting, Chicago, USA, pp.2655-2660 (2001)

( 8 ) S.M. Silva, B.M. Lopes, B.J.C. Filho, R.P. Campana, and W.C. Boaventura: "Performance Evaluation of PLL Algorithms for Single-Phase GridConnected Systems", in Conf. Record of IEEE-IAS Annual Meeting, Seattle, USA, pp.2259-2263 (2004)

( 9 ) R.S. Zhang: "Control of Single Phase Power Converter in d-q Rotating Coordinates", United States Patent, No. US 6,621,252 B2 (2003)

(10) M. Saitou and T. Shimizu: "Generalized Theory of Instantaneous Active and Reactive Powers in Single-Phase Circuits based on Hilbert Transform", in Proc. IEEE Power Electron. Spec. Conf., Vol.3, pp.1419-1424 (2002)

(11) M. Saitou and T. Shimizu: "A Control Method of Single Phase Power Active Filter on d-q Coordinate with Hilbert Transformer", IEEJ Trans. IA, Vol.122, No.2, pp.193-194 (2002) (in Japanese)

(12) NiPPON CHEMI-CON CORPORATION http://www.chemi-con.co.jp/e/catalog/pdf/al-e/al-all-e1001n-130701.pdf

(13) GS Yuasa Corporation http://www.gs-yuasa.com/us/technic/vol8/pdf/008_01_060.pdf

(14) Japan Electric Association, Indoor Wiring Guidelines, JESC E0005, p.32 (2005) (in Japanese)

(15) IEEE 519-1992, "Recommended Practices and Requirements for Harmonic Control in Electrical Power System" (1992)

Hidenori Tanaka (Student Member) was born in 1990. He re-

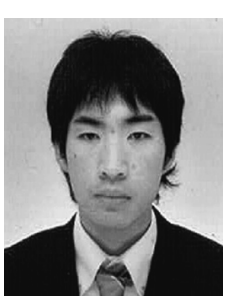
ceived the B.S. and the M.S. degrees in Electrical and Electronic Engineering from Yamaguchi University, Japan, in 2012 and 2013, where he is currently pursuing the Ph.D. degree. His current research interests include an active power quality compensator in single-phase three-wire distribution systems. He is a student member of the IEE of Japan.

Takaaki Wakimoto (Student Member) was born in 1990. He received

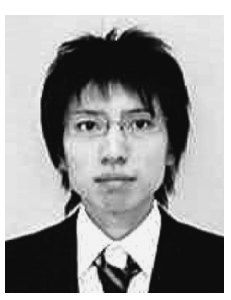
the B.S. degree in Electrical and Electronic Engineering from Yamaguchi University, Japan, in 2013, where he is currently pursuing the M.S. degree. His current research interests include suppressing voltage swell caused by PV generators with reactive power control. He is a student member of the IEE of Japan.

Toshihiko Tanaka (Senior Member) was born in 1959. He received

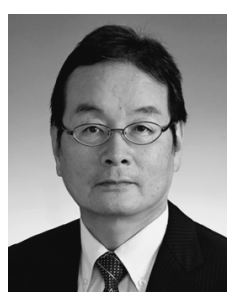
the M.S. degree in electrical engineering from Nagaoka University of Technology in 1984, and the $\mathrm{Ph}$.D. degree from Okayama University in 1995 . He joined Toyo Denki Manufacturing Co. in 1984. From 1991 to 1997, he was an Assistant Professor at the Polytechnic University of Japan. From 1997 to 2004, he was an Associate Professor at Shimane University. Since 2004, he has been a Professor at Yamaguchi University. His research interests are harmonics generated by static power converters and their compensation. He is a member of the IEEE.

Masayuki Okamoto (Member) was born in 1971. He received the

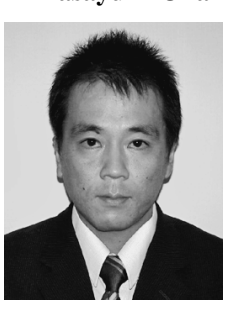
M.S. and Ph.D. degrees in electrical engineering from Yamaguchi University in 1996 and 1999, respectively. From 1999 to 2012, he was an Assistant Professor at Yamaguchi University. Since 2012, he has been an Associate Professor at Ube National College of Technology. His research interests include device modeling of GaN-based switching devices and design of a high frequency power electronic converter with the switching devices. He is a member of the IEEE.

Eiji Hiraki (Member) was born in 1964. He received the M.S. and

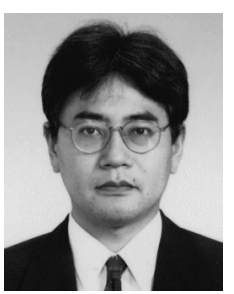

IEEE. $\mathrm{Ph} . \mathrm{D}$. degrees in electrical engineering from Osaka University in 1990 and 2004, respectively. From 1995 to 2007, he was a Research Associate with the Power Electronics Laboratory at Yamaguchi University, where he was an Associate Professor from 2007 to 2013. He is currently a Professor at Okayama University. His research interests include the softswitching technique for high-frequency switching power conversion systems. $\mathrm{He}$ is a member of the 